\title{
Synergy Effect of Combination of Fractional CO2 and Fractional Q-switched Ruby Laser Treatment for Skin Rejuvenation
}

\author{
Seyoung Kim \\ Eunsoo Park \\ Seungmin Nam
}

Department of Plastic and Reconstructive Surgery, College of Medicine, Soonchunhyang University, Soonchunhyan University Bucheon Hospital, Bucheon, Korea
Received June 5, 2015

Revised June 13, 2015

Accepted June 15, 2015

\section{Correspondence}

Eunsoo Park

Department of Plastic and Reconstructive Surgery, Soonchunhyang Univsersity Bucheon Hospital, 1174, Jung-dong,Wonmi-gu, Bucheon 420-767, Korea

Tel: +82-32-621-5319

Fax: $+82-32-621-5016$

E-mail: peunsoodaschmc.ac.kr

(c) Korean Society for Laser Medicine and Surgery

(c) This is an open access article distributed under the terms of the Creative Commons Attribution NonCommercial License (http://creativecommons.org/ licenses/by-nc/4.0) which permits unrestricted noncommercial use, distribution, and reproduction in any medium, provided the original work is properly cited.

\section{Background and Objectives}

Fractional photothermolysis is an important laser modality in the management of several skin conditions and photoaging. Fractional photothermolysis, in the Asian population, has shown significant improvement in facial skin texture and overall skin tone, but not in dyschromia or facial lentigines. Therefore, additional treatment is needed for facial lentigines.

\section{Materials and Methods}

For combined laser therapy, the treatment included 3-4 treatment sessions with fractional $\mathrm{CO}_{2}$ laser and 2-3 treatment sessions with fractional $Q$-switched ruby laser at 4-week intervals. Treatment with two types of devices was performed alternately.

\section{Results}

The majority of patients obtained a satisfactory appearance after the final treatment. Regarding objective improvement, 5 patients (20\%) had "Near total improvement" at the end of treatment. Fifteen patients (60\%) and 5 patients (20\%) had "Marked improvement" and "Moderate improvement", respectively. None of them showed any obvious side effects.

\section{Conclusion}

The use of combined fractional $\mathrm{CO}_{2}$ and fractional Q-switched ruby laser for treatment of photoaging showed successful results, including enhanced skin texture and removal of pigmentation.

\section{Key words}

Fractional $\mathrm{CO}_{2}$ laser; Fractional Q-switched ruby laser; Pigmentation; Resurface 


\section{INTRODUCTION}

The term photoaging describes damage to the skin caused by intense and chronic exposure to sunlight. The visible effects of photoaging are fine wrinkles, mottling, pigmentation and roughness of the skin. These changes are usually associated with chronologic aging. However, photoaging is not a good indicator of chronologic age. It just makes a person look older than his or her chronologic age.

Fractional photothermolysis is an important laser modality in the management of several skin conditions and photoaging. Fractional photothermolysis, in the Asian population, has shown significant improvement in facial skin texture and overall skin tone. ${ }^{1}$ However, there is not much improvement in dyschromia or facial lentigines. ${ }^{2}$ Therefore, additional treatment is needed for facial lentigines. The Q-switched ruby laser has been effective for treating many pigmented epidermal and dermal lesions, including lentigines. ${ }^{3,4}$

The purpose of this study is to review our clinical experience of the effect of combination of fractional $\mathrm{CO}_{2}$ and fractional $\mathrm{Q}$-switched ruby laser treatment for skin rejuvenation.

\section{MATERIALS AND METHODS}

This is an observational study performed in the department of plastic and reconstructive surgery, Soonchunhyang hospital. 25 women (mean age 49.2 years, range 3464 years; Fitzpatrick skin type III to IV) had been treated in this method of combination of fractional $\mathrm{CO}_{2}$ and fractional Q-switched ruby laser treatment from April, 2012 to February, 2013. Photoaging is defined as facial hyperpigmentation with shallow coloring large pore size, striations, rhytide or acne scarring. Exclusion criteria for this study included Fitzpatrick skin type V to VI, history of significant active acne, malignant or premalignant skin lesion, use of isotretinoin within 12 months or pregnancy.

Occlusive application of topical anesthetic cream leutectic mixture of lidocaine and prilocaine; EMLA ${ }^{\circledR}$ cream 5\%, AstraZeneca, Sweden) was performed 1 hour before each procedures. Patients were treated on the entire face with both laser modalities. For combined laser therapy, the treatment included 3-4 treatment sessions with fractional $\mathrm{CO}_{2}$ laser and 2-3 treatment sessions with fractional $Q$-switched ruby laser at 4 week intervals. Treatment with two type devices was performed alternately. Patients were treated with fractional $\mathrm{CO}_{2}$ laser (LineXel ${ }^{\circledR}$; UTI Co. Ltd, Korea) for facial skin resurfacing. The laser procedure was performed with a pulse duration of $180-220 \mathrm{~ms}$, with a distance between spots of $0.8-0.9 \mathrm{~mm}$, and spot size of $1 \mathrm{~mm}$ (1st degree). For pigmented skin lesion, the fractional Q-switched ruby laser (Melastar ${ }^{\circledR}$; Asclepion Co. Ltd., Germany) was used. The laser parameters for the present study were set as follows: wavelength of $694 \mathrm{~nm}$, spot size of $7.1 \times 7.1 \mathrm{~mm}$, a pulse width of $25-40 \mathrm{~ns}$, a fluence of $4.0-5.0 \mathrm{~J} / \mathrm{cm}^{2}$ and a repetition rate of $1.5 \mathrm{~Hz}$. After treatment, the treated areas were cooled with ice packs and a sunscreen was applied throughout the treatment period.

Clinical photographs were used to evaluate patient satisfaction and objective improvement of facial wrinkle lines, skin texture and pigmentation with clinical photographs. Photographs (Nikon D90 digital camera, Japan) were taken under identical settings at baseline evaluation, every treatment visit (before and after session) and 1 month after the last session.

Patient satisfaction was categorized as "none, fair, good and excellent". An experienced independent physician assessed clinical improvement of treatment areas using photographic review. Results were classified as grade I (<25\%, minimal to no improvement), grade I| (25-50\%, moderate improvement), grade III (50-75\%, marked improvement) and grade IV (>75\%, near total improvement). Any side effects were also noted.

\section{RESULTS}

Most patients obtained a satisfactory appearance after the final treatment. Of 25 patients, 7 patients (28\%) were in "excellent", 13 patients (52\%) were in "good", 4 patients (16\%) were in "fair", and 1 patient (4\%) showed "none" in patient satisfaction, respectively. There was "near total improvement" objective improvement in 5 patients $(20 \%)$ at the end of treatment. 15 patients $(60 \%)$ and 5 patients (20\%) had "marked improvement" and "moderate improvement", respectively (Figs. 1-3).

None of them showed any obvious side effects. The most frequent side effect was transient erythema. Transient erythema that lasted for 3-4 days was reported by $80 \%$ of the patients treated with fractional $\mathrm{CO}_{2}$ laser, whereas transient erythema that lasted for 2-3 days was reported by $10 \%$ of the patients treated with fractional $Q$-switched ruby laser. Edema that lasted for 2-7 days was reported by 3 patients who were treated with fractional $\mathrm{CO}_{2}$ laser. All adverse effects were mild and lasted for less than 1 week. There was transient hyperpigmentation in 3 patients, but the worsening of the pigmentation was not severe, and all patients completely healed within 10-14 days. 

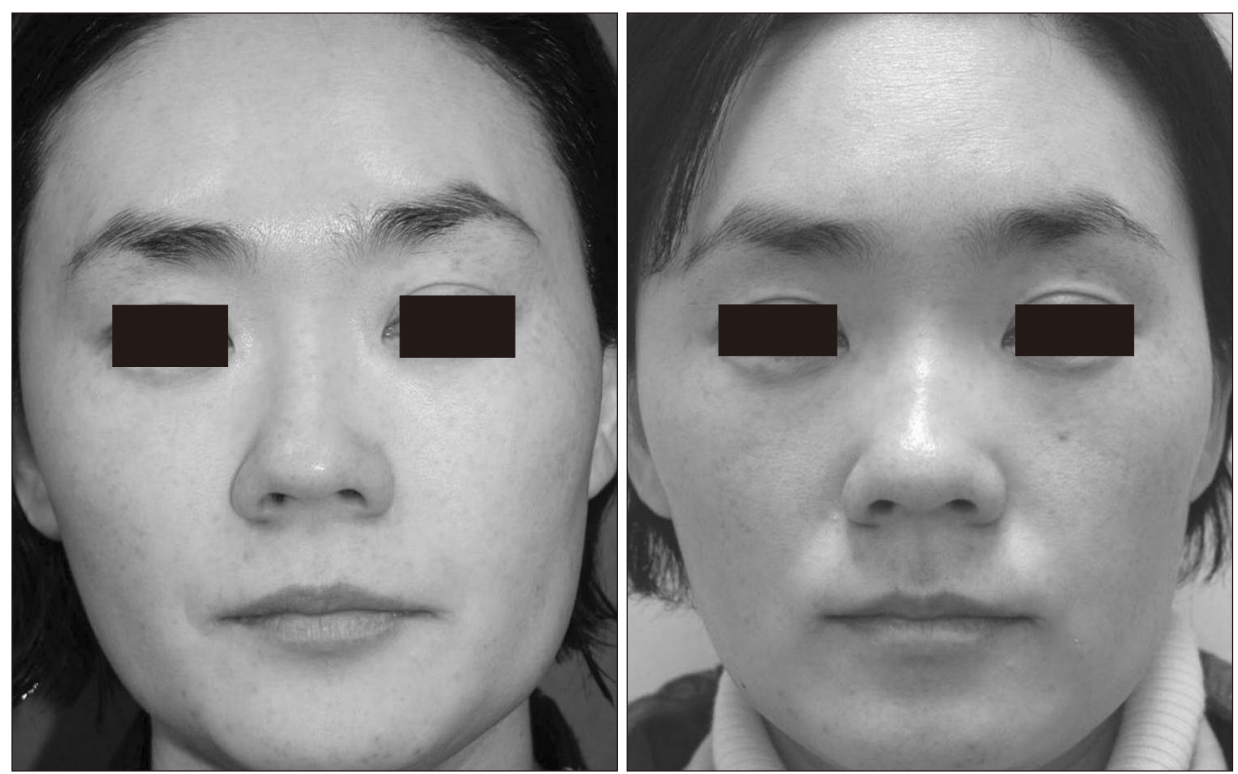

Fig. 1. Clinical appearance of 46 yearold female (Left) Baseline (Right) One month after final treatment.
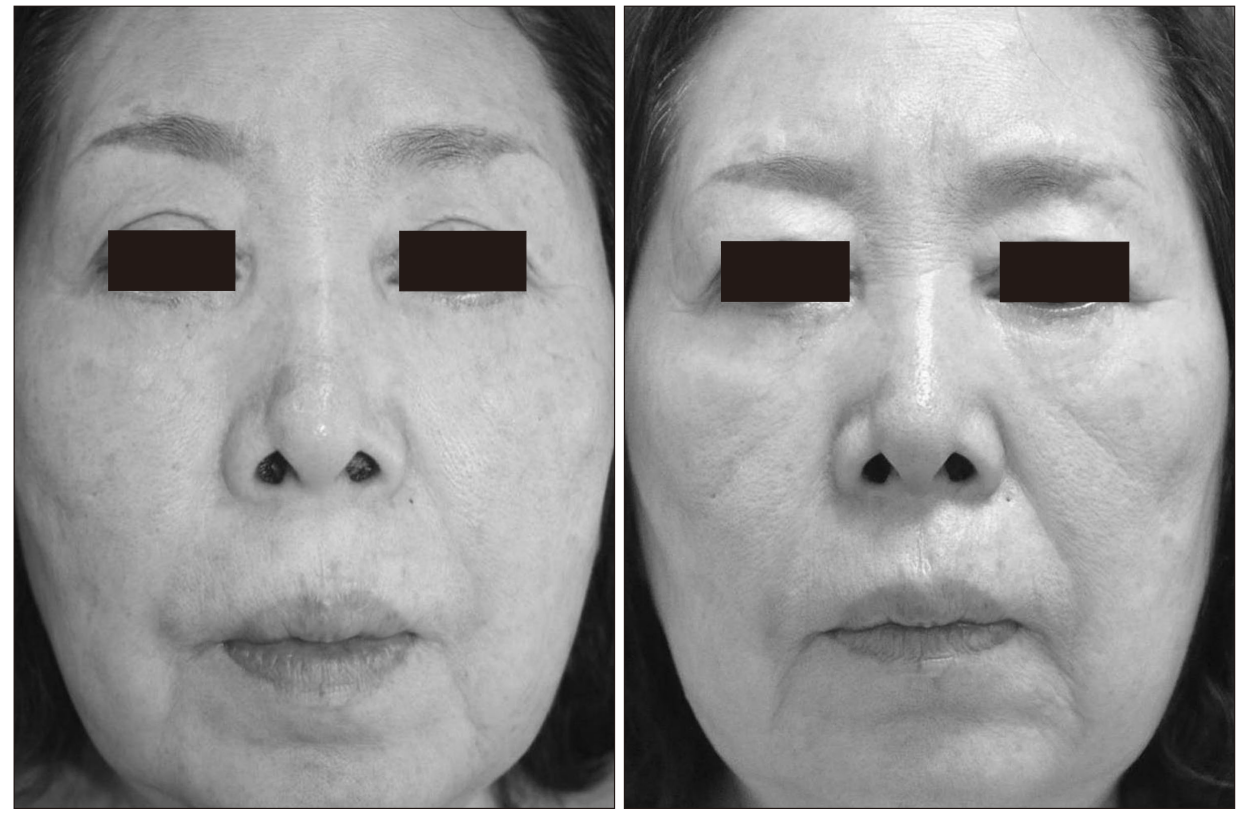

Fig. 2. Clinical appearance of 72 yearold female (Left) Baseline (Right) One month after final treatment.
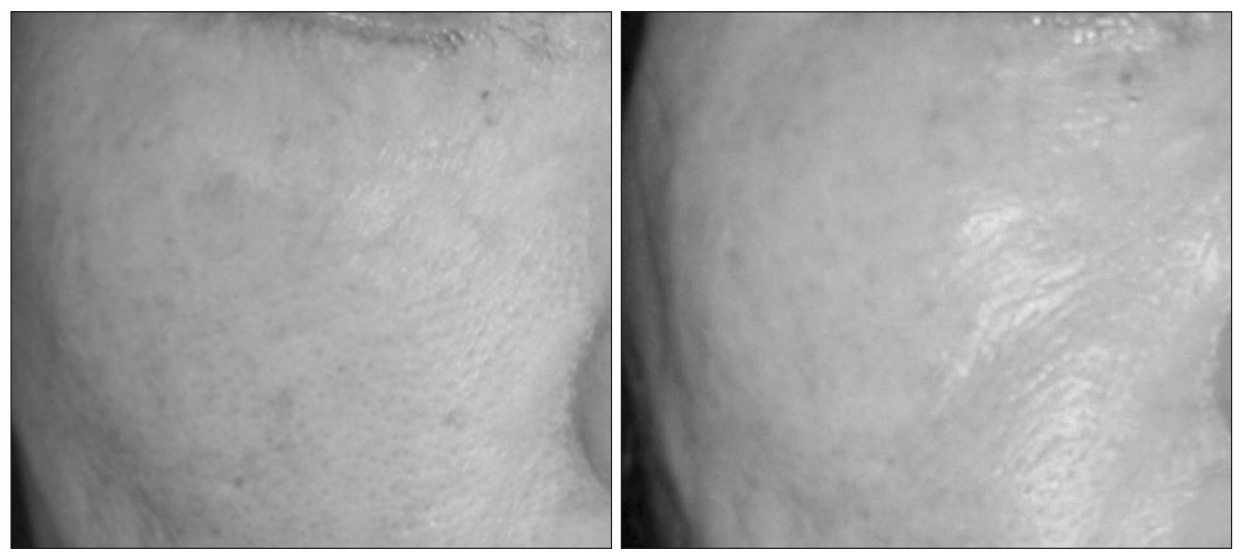

Fig. 3. Clinical appearance of 72 yearold female (Left) Baseline (Right) One month after final treatment. Not only skin texture, also pigmented lesion was improved. 


\section{DISCUSSION}

Fractional photothermolysis has become an important laser modality in management of a number of skin conditions and photoaging. Fractional photothermolysis is the fractional emission of light into microscopic treatment zones, creating small columns of injury to the skin in a pixilated fashion. ${ }^{5}$ Epidermal and dermal disruptions occur in these focal zones of thermal injury, stimulating dermal collagen production and elastic tissue formation. ${ }^{6.7}$ Fractional photothermolysis has been used successfully to treat photodamage and overall dyschromia in the Caucasian population. ${ }^{8-10}$ In the Asian population, there has been a significant improvement in facial skin texture and overall skin tone. 'However, there is not much improvement in dyschromia or facial lentigines. ${ }^{2}$ Therefore, additional treatment is needed for facial lentigines.

Based on our clinical experience, combination of $\mathrm{CO}_{2}$ fractional laser and fractional $\mathrm{Q}$-switched ruby laser treatment resulted in significant improvement of not only skin texture, but also multiple pigmented lesions without unremarkable side effects. The $\mathrm{Q}$-switched ruby laser, especially in the fractional mode, has been effective in treating pigmented lesions. It is thought that treatment with a $694 \mathrm{~nm}$ Q-switched ruby laser with fractional mode can effect in pigmented dermal lesions. Therefore, fractional Q-switched ruby laser has been effective in treating many pigmented lesions, including lentigines. ${ }^{3,4}$ This combined technique has a disadvantage in treatment session times, but it has an advantage in reducing side effects and obtaining reliable results. This combination therapy, including the use of $\mathrm{CO}_{2}$ fractional laser and fractional $\mathrm{Q}$-switched ruby laser, has been an effective treatment option for patients who want refinement of their pigmented skin lesion as well as facial rejuvenation.

\section{CONCLUSION}

The use of combined fractional $\mathrm{CO}_{2}$ and fractional Q-switched ruby laser for the treatment of photoaging drew successful results, such as enhanced skin texture and removal of pigmentation.

\section{ACKNOWLEDGMENTS}

This work was supported by the Soonchunhyang University Research Fund.

\section{REFERENCES}

1. Lapidoth M, Yagima Odo ME, Odo LM. Novel use of erbium:YAG (2,940-nm) laser for fractional ablative photothermolysis in the treatment of photodamaged facial skin: a pilot study. Dermatol Surg 2008;34:1048-53.

2. Lee HS, Won CH, Lee DH, An JS, Chang HW, Lee JH, et al. Treatment of melasma in Asian skin using a fractional 1,550-nm laser: an open clinical study. Dermatol Surg 2009;35:1499-504.

3. Schoenewolf NL, Hafner J, Dummer R, Bogdan Allemann I. Laser treatment of solar lentigines on dorsum of hands: QS Ruby laser versus ablative $\mathrm{CO} 2$ fractional laser - a randomized controlled trial. Eur J Dermatol 2015;25:122-6.

4. Sadighha A, Saatee S, Muhaghegh-Zahed G. Efficacy and adverse effects of $\mathrm{Q}$-switched ruby laser on solar lentigines: a prospective study of 91 patients with Fitzpatrick skin type II, III, and IV. Dermatol Surg 2008;34:1465-8.

5. Hantash BM, Bedi VP, Kapadia B, Rahman Z, Jiang K, Tanner H, et al. In vivo histological evaluation of a novel ablative fractional resurfacing device. Lasers Surg Med 2007;39:96-107.

6. Laubach HJ, Tannous Z, Anderson RR, Manstein D. Skin responses to fractional photothermolysis. Lasers Surg Med 2006;38:142-9.

7. Bogdan Allemann I, Kaufman J. Fractional photothermolysis-an update. Lasers Med Sci 2010;25:137-44.

8. Tierney EP. Hanke CW. Review of the literature: Treatment of dyspigmentation with fractionated resurfacing. Dermatol Surg 2010;36:1499-508.

9. Karsai S, Fischer T, Pohl L, Schmitt L, Buhck H, Jünger M, et al. Is non-ablative 1550-nm fractional photothermolysis an effective modality to treat melasma? Results from a prospective controlled single-blinded trial in 51 patients. J Eur Acad Dermatol Venereol 2012;26:470-6.

10. Hilton S, Heise H, Buhren BA, Schrumpf H, Bölke E, Gerber PA. Treatment of melasma in Caucasian patients using a novel 694-nm Q-switched ruby fractional laser. Eur J Med Res 2013; 18:43. 